\title{
The role that oilseeds, including new hi-oleic varieties can play in improving the profile of fat intake by the UK population
}

Janice Irene Harland

HarlandHall Associates, Cirencester, UK; jan.harland@harlandhall.co.uk

Received 23 December 2013; revised 23 January 2014; accepted 5 February 2014

Copyright (c) 2014 Janice Irene Harland. This is an open access article distributed under the Creative Commons Attribution License, which permits unrestricted use, distribution, and reproduction in any medium, provided the original work is properly cited. In accordance of the Creative Commons Attribution License all Copyrights (C) 2014 are reserved for SCIRP and the owner of the intellectual property Janice Irene Harland. All Copyright (C) 2014 are guarded by law and by SCIRP as a guardian.

\section{ABSTRACT}

The production in the EU of the oilseeds, rapeseed and sunflower, has increased dramatically over the last 20 years. Much of the oil produced after crushing is used for culinary purposes; this enhanced intake of vegetable oil has led to a substantial change of fatty acid (FA) supply. This has been conclusively demonstrated by taking the UK oil supply data and by use of the FA profile of the key oils converting the supply data into a FA profile of the UK market place for 20082012. The most marked changes are a reduction in saturated fat (SFA) and an increase in monounsaturated fatty acids (MUFA) available for consumption. Furthermore the introduction of varieties of hi-oleic sunflower oil can further affect the market FA profile. The fat profiles of rapeseed and sunflower oils are considered healthy and they can have a positive impact when included in the diet, particularly as a replacement for oils or fats rich in SFA. In the UK and much of Europe, adult SFA intake continues to exceed recommendations. While reductions in the UK population's SFA intake have occurred over the last 20 years, these are modest and it may be timely to identify ways in which SFA intake can be further reduced. To do this, the UK market FA supply data has been analysed alongside the profile of FA intake from adults recording their intake in national dietary surveys in order to identify if the market supply affects overall FA consumption. There is an indication that market oil supply is reflected in adults dietary intake of the main groups of FA. Consequently changes made to the oil profile of oilseeds by plant breeders and use of the resulting healthier oils by food manufacturers could have important roles to play in helping adults to achieve the recommended intake of SFA and also improve the overall fat quality in their diet leading to enhanced long-term health and well-being. Thus changes made in primary oilseed production supported by culinary use of these oils with a healthier profile could help support the UK's Department of Health SFA Responsibility Deal and other similar National initiatives that are looking for industry pledges to offer sustained long-term reductions in SFA, consistent with healthy eating recommendations. Using the market supply to drive dietary change allows sectors of the population to be most resistant healthy eating messages and least likely to make dietary interventions to move to a healthier FA profile of intake with minimal personal intervention; in this case, health by stealth.

\section{KEYWORDS}

Rapeseed; Sunflower; Vegetable Oil; Hi-Oleic; Healthy-Eating; Dietary-Intervention

\section{INTRODUCTION}

Changing the fat content of the diet has been the cornerstone of dietary advice for the last half century. The Committee on Medical Aspects of Food Policy (COMA) dietary reference value (DRV) of 35\% energy (E) intake as fat [1], has been broadly achieved by the population as a whole in the UK [2]. With the result that in recent times the message has changed to focus more on fat quality, rather than the amount per se, advice remains to reduce SFA intake to a recommended intake of around $10 \% \mathrm{E}$ 
$[1,3]$.

The major dietary sources of SFA have conventionally been considered to be meat and dairy products, although progress has been made to increase the consumption of lower fat dairy products such as semi-skimmed and skimmed milk, low fat yoghurts and desserts and lower fat alternatives to butter. In addition, people have made lower fat choices in the meat sector, by increasing the consumption of lean meats, such as chicken breasts and reducing the amount of fatty cuts of meats.

Over the twenty plus years since the COMA DRV report, there have been significant other changes in the fat profile in the diet, it is suggested that these largely result from the greater use of plant-derived oils, mainly from oilseeds, such as rapeseed, sunflower and soya, but also palm oil. Figure 1 shows the vegetable oil supply data, from which it can be seen that the use of vegetable oil has increased dramatically in the EU. It can be seen that during a 30-year period, there has been a four-fold increase in the vegetable oil supply, a seven-fold increase in rapeseed oil use and a three-fold increase in sunflower oil, with only a marginal increase in soya oils, largely due to concern about genetical modification. The other major change is the nearly 10 -fold increase in palm oil use, as animal fats such as fish and tallow were phased out.

All plant-derived oils are typically $>99 \%$ fat, but each has a characteristic FA profile, that differentiates it from the other oils and also influences the uses, in this context, the culinary uses for which the oil is suitable. Much of the oil from oilseeds is used in food manufacture; as an ingredient in recipes, for frying, in salad dressings and in the production of margarines and spreads. While all oils are not suitable for all purposes there are considerable opportunities to switch between oils or blend oils to meet technological requirements, however the extent to which this switching between sources could be used to influence the FA profile in the diet has not been examined to the same degree. This review will address the extent to which using the oilseeds produced within the EU can potentially impact on the fat profile of diet, with specific focus on the UK.

\section{OILSEEDS}

\subsection{EU Market/UK Edible Oil Market}

Once crushed oilseeds provide the Food Industry with high quality edible oil rich in unsaturated FA. The principle oils used in the EU are rape, palm and sunflower. Data related to the oil supply can be seen in dramatically from around 5 million tonnes in 1980 to 22 million tonnes in 2012. Over this 30-year period, the most significant change in the market has been an increase in both the amount and proportion of rapeseed in the market. By reference to the UK market, vegetable oil used for edible purposes has been calculated for the five-year period 2008-2012, see Figure 2. The trend of use for food purposes in the UK follows that seen for the market as a whole with rapeseed, palm and sunflower oils being the most important. There is also significant use of soya oil, but this has tended to remain at a fairly constant level.

Although not reflected in the market statistics, another significant change has taken place and this is the increase in hi-oleic oilseeds, particularly sunflower. Industry sources estimate than during 2012-2013 approx. one third of sunflower oil used in the food industry is from hi-oleic varieties. This has implications in respect of the fat profile of the edible oils used in food manufacture as the market place.

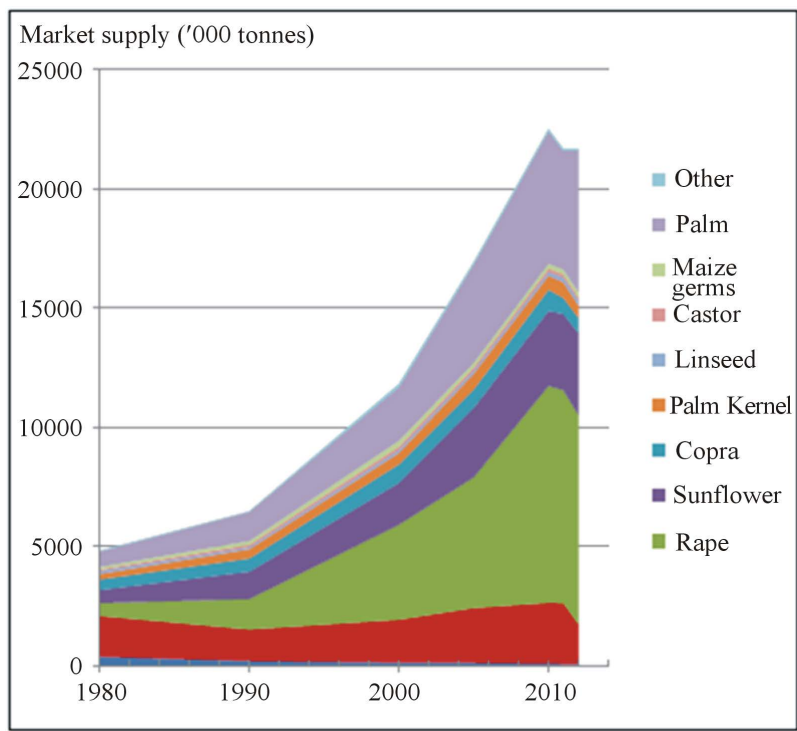

Figure 1. Total EU supply of vegetable oils and fats 1980-2012 (Source FEDOIL, www.fediol.org/).

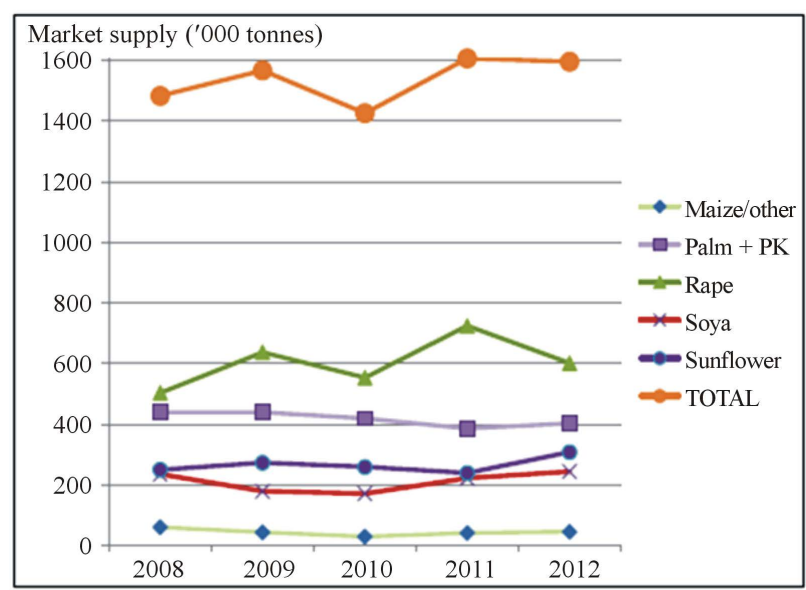

Figure 2. UK vegetable oils and fats use for edible purposes 2008-2012 (Source FEDOIL, www.fediol.org/)). 


\subsection{Nutrition Profile}

The main nutrients supplied by vegetable oils are fats and thereby they are a major source of energy in the diet, and vitamin E present as alpha and delta tocopherol, which also have antioxidant properties. Other microcomponents may also have beneficial health properties, for example, the polyphenols in olive oil (hydroxytyrosol and its derivatives) have been shown to have antioxidant properties [4]. Dietary fats mainly consist of triacylglycerol, which are molecules composed of three fatty acids and glycerol and are a major energy source for the body. Fatty acids can be classified according to their number of double bonds; SFA have no double bonds, MUFA have one double bond and polyunsaturated fatty acids (PUFA) have two or more double bonds. The position of the double bond can vary along the carbon chain, typically counting starts from the methyl-end (-CH3), hence, "n-9" means that the double bond is located at the ninth carbon atom from the methyl-end. The double-bond positions most frequently referred to are n-3, n-6 and n-9 and are most prevalent in the diet as the 18-carbon fatty acids, for example, n-3, alpha linolenic acid (ALA); n-6, for example, linoleic (LA) and n-9, oleic acid.

The FA profile of the main vegetable oils used in the food industry varies considerably and can have a major impact on nutrient intake, see Table 1 for details of the fatty acid content of vegetable oils, also included for comparison is the composition of lard traditionally used for frying chips in the UK.

There is little hydrogenated soya oil used in the UK, because of its high content of trans fat and also concerns about genetic integrity, with the result that alternatives have been found. Olive oil is often the oil of choice within the home, where it is used primarily for salad dressings, but also single-use frying. While olive oil has a healthy image it can be seen that it is considerably higher in SFA content, than either rapeseed or sunflower oils. Rapeseed oils typically have half the SFA content of olive oil and at $>7 \%$ SFA contain only around $15 \%$ of the SFA found in palm or palm olein ( 45\% SFA).

Developments in plant breeding have led to the development of hi-oleic sunflower and hi-oleic rapeseed oils.

These differ in fatty composition by, as the name suggests, containing a higher proportion of their FA as the MUFA, oleic acid. These oils are generally lower in SFA and suitable for a wider range of food uses.

Another important aspect of the FA profile relates to the content of n-3 PUFA. It is considered that the dietary intake of this group of FA is barely adequate in many European populations [5], while oily fish and fish oils are the main dietary source of the long chain n-3 PUFA, the major sources of ALA are linseeds, rapeseed oil, soya oil and walnuts, of these, rapeseed is by far the most
Table 1. Fat content of oils used for domestic or commercial food manufacture.

\begin{tabular}{|c|c|c|c|c|c|c|c|}
\hline Oil & $\begin{array}{c}\text { Total } \\
\text { fat }\end{array}$ & SFA & TFA & MUFA & PUFA & $\begin{array}{c}\text { PUFA: } \\
\text { n-6 }\end{array}$ & $\mathrm{n}-3$ \\
\hline \multicolumn{8}{|c|}{$\mathrm{g} / 100 \mathrm{~g}$} \\
\hline Rapeseed oil & 99.9 & 6.6 & $\operatorname{Tr}$ & 59.2 & 29.3 & 19.7 & 9.6 \\
\hline $\begin{array}{l}\text { HO rapeseed } \\
\text { oil }\end{array}$ & 99.5 & 6.5 & $\operatorname{Tr}$ & 72.0 & 21.0 & 18.0 & 3.0 \\
\hline $\begin{array}{l}\text { Sunflower } \\
\text { oil }\end{array}$ & 99.9 & 12.0 & $\operatorname{Tr}$ & 20.5 & 63.3 & 63.2 & 0.1 \\
\hline $\begin{array}{l}\text { Commercial } \\
\text { sunflower }^{*}\end{array}$ & 100 & 9.0 & 0.2 & 57.3 & 29.0 & 28.7 & $<0.1$ \\
\hline $\begin{array}{l}\text { Hi-oleic } \\
\text { sunflower }\end{array}$ & 100 & 9.7 & $<1$ & 83.6 & 3.8 & 3.6 & 0.2 \\
\hline $\begin{array}{l}\text { Omega-9 } \\
\text { sunflower }\end{array}$ & 99.5 & 3.3 & $<1$ & 92.0 & 5.0 & 4.8 & 0.2 \\
\hline Palm & 99.9 & 47.8 & $\operatorname{Tr}$ & 37.1 & 10.4 & 10.1 & 0.3 \\
\hline Palm olein & 100 & 45.1 & $<1$ & 42.3 & 9.6 & 9.1 & 0.2 \\
\hline Soya oil & 99.9 & 15.6 & $\operatorname{Tr}$ & 21.2 & 58.8 & 51.5 & 7.3 \\
\hline Olive oil & 99.9 & 14.3 & $\operatorname{Tr}$ & 73.0 & 8.2 & 7.5 & 0.7 \\
\hline PH soya* & 100 & 15.4 & 10.8 & 34.6 & 45.2 & 38.9 & 3.8 \\
\hline $\begin{array}{l}\text { Groundnut } \\
\text { (peanut) }\end{array}$ & 99.9 & 20.0 & $\operatorname{Tr}$ & 44.4 & 31.0 & 31.0 & 0.0 \\
\hline Corn oil & 99.9 & 14.5 & $\operatorname{Tr}$ & 29.9 & 51.3 & 50.4 & 0.9 \\
\hline Lard & 99.0 & 40.6 & 0.0 & 42.9 & 9.8 & 9.2 & 0.5 \\
\hline
\end{tabular}

(Analysis from McCance and Widdowson: Fatty Acids: Supplement to the Composition of Foods: Fatty Acids Supplement to 5th edition, except as indicated to the contrary, ${ }^{*}$ USDA database,

http://www.nal.usda.gov/fnic/foodcomp/ ${ }^{* *}$ Industry sources.) PUFA polyunsaturated fatty acids; comprising n-6 PUFA and n-3 PUFA, Tr: trace.

prevalent in the diet.

\section{FAT RECOMMENDATIONS}

A significant review of evidence related to fats in the diet was conducted under the auspices of Food and Agriculture Organization (FAO) and World Health Organization (WHO), who held an expert consultation on fats and fatty acids in human nutrition in the last quarter of 2008 [3]. This was the first consultation to be held since 1993. The key recommendations of this review are shown in Table 2.

In terms of nutrient intake, a summary of the major findings identified that replacing SFA (of chain length C12:0-C16:0) in the diet with PUFA and to a lesser extent MUFA decreases low density lipoprotein cholesterol (LDL-C) concentration and the total/high density lipoprotein (HDL) cholesterol ratio, as a result, a limit of $10 \%$ $\mathrm{E}$ as SFA was recommended. There is also convincing evidence, even more so than had been thought in the past, that TFA from commercial partially hydrogenated vegetable oils (PHVO) increase coronary heart disease (CHD) 
Table 2. Adult recommended dietary intakes for total fat and fatty acid intake.

\begin{tabular}{cc}
\hline Type of fat & $\begin{array}{c}\text { Recommended } \\
\text { intake }\end{array}$ \\
\hline Total fat & $20 \%-35 \% \mathrm{E}$ \\
SFA & $10 \% \mathrm{E}$ \\
MUFA & By difference \\
Total PUFA & $6 \%-11 \% \mathrm{E}$ \\
(LA + ALA + EPA + DHA) & $2.5 \%-9 \% \mathrm{E}$ \\
Of which: n-6 PUFA & $0.5 \%-2 \% \mathrm{E}$ \\
n-3 PUFA & $>0.5 \% \mathrm{E}$ \\
ALA & $0.25-2 \mathrm{~g} / \mathrm{d}$ \\
EPA + DHA & $<1 \% \mathrm{E}$ \\
TFA &
\end{tabular}

*The determination of intake of MUFA is unique in that it is calculated by difference, i.e. MUFA = Total fat intake (\%E) - SFA (E\%) - PUFA (E\%) TFA (\%E). Therefore, the MUFA intake resulting may cover a wide range depending on the total fat intake and dietary fatty acid pattern. LA linoleic acid, ALA alpha linolenic acid, EPA eicosapentaenoic acid; DHA docosahexaenoic acid (Source FAO 2010).

risk factors and events, leading to an intake recommendation of $>1 \%$ E.

The overall intake range for fat was proposed to be $20 \%$ - $35 \% \mathrm{E}$, in recommending this range the authors acknowledged the need to ensure adequate consumption of total energy, essential fatty acids, and fat soluble vitamins for most individuals and specifically for women of reproductive age and adults with body mass index (BMI) $<18.5$; it was suggested that a maximum intake of $30 \%$ $35 \% \mathrm{E}$ was appropriate for most individuals. A recent systematic review of dietary reference intakes, nutritional goals and dietary guidelines for fat and fatty acids identified that was similarity in recommendations given for total fat intake, SFA and TFA, but a greater variation in values for PUFA, and MUFA [6].

Convincing evidence that LA and ALA are indispensable was cited in the FAO report and, since they cannot be synthesised by humans, there was sufficient evidence to set an acceptable intake to meet essential FA needs for linoleic LA and ALA consumption [3]; these are respectively $2.5 \% \mathrm{E}$ LA and $0.5 \% \mathrm{E}$ ALA, see also the EFSA review of DRV for fats [7]. The minimum recommended value of total PUFA consumption for lowering LDL and total cholesterol concentrations, increasing HDL-cholesterol concentrations and decreasing the risk of CHD was considered to be $6 \%$ E. High consumption was suggested to be $>11 \% \mathrm{E}$, at which level there was a concern related to lipid peroxidation, thus the recommended range for PUFA was established at $6 \%-11 \% \mathrm{E}$.

The determination of intake of MUFA is unique in that it is calculated by difference, where MUFA = Total fat intake (\%E) - SFA (\%E) - PUFA (\%E) - TFA (\%E). It was recognised that MUFA intake may cover a wide range depending on the total fat intake and dietary fatty acid pattern and that intakes of $15 \%$ - $20 \%$ may result. However, in addition to dietary requirements for total fat and FA, the consultation identified that food-based dietary guidelines are essential for promoting health and preventing disease. Although this area was not reviewed, a general recommendation to follow a dietary pattern predominantly based on whole foods (i.e., fruits and vegetables, whole grains, nuts, seeds, legumes, other dietary fibre sources, n-3 PUFA-rich seafood) with a relatively lower intake of energy dense processed and fried foods, and sugar-sweetened beverages, was given. Also the avoidance of large portion sizes and moderation in the consumption of dairy products, lean meats and poultry was proposed.

Nutrient recommendations were also reviewed recently in Scandinavia, Nordic Nutrient Recommendations (NNR) [8]. In 2013, the new NNR included a fundamental change in approach, by placing the whole diet in focus. Dietary patterns were recommended as well as nutrient intakes and physical activity, all of which will contribute to overall good health.

NRR, in common with FAO, suggested that features of a healthy dietary pattern include plenty of vegetables, fruit and berries, pulses, regular intake of fish, vegetable oils, wholegrain, low-fat alternatives of dairy and meat, and limited intake of red and processed meat, sugar, salt and alcohol. From a nutrient perspective the key change was an emphasis on fat and carbohydrate quality, specifically favouring MUFA, PUFA, and dietary fibre and encouraging a limited intake of SFA, TFA and added sugars. Recommendations for SFA and TFA were $>10 \%$ E and PUFA 5\% - 10\% E of which n-3 fatty acids should provide at least $1 \% \mathrm{E}$. The recommended intake range for MUFA has been increased from $10 \%-15 \%$ E to $10 \%$ - $20 \%$ E. In reviewing the evidence to reach this conclusion the NNR panel stated that partly replacing SFA with PUFA and MUFA (oleic acid) from vegetable dietary sources (e.g., olive or rapeseed oils) was an effective way of lowering the serum LDL-C concentration and decreasing the LDL/HDL-C ratio. Replacing SFA and TFA with PUFA reduces the risk of coronary heart disease and replacement of SFA and TFA with MUFA from vegetable dietary sources (e.g., olive or rapeseed oils) has similar effects. Their recommended range for the total amount of fat intake was $25 \%-40 \% \mathrm{E}$ based on the sum of the ranges of the recommendations for individual fatty acid categories and a suitable target for dietary planning is a fat intake of 32\% - 33\% E.

The approach suggested by NRR builds on an approach suggested in 2005 by the BNF [9] in their Task Force report, Cardiovascular Disease: Diet, Nutrition and Emerging Risk Factors. This report emphasised the importance of fat quality although this recommendation 
has taken time to gain widespread adoption.

National recommendations throughout Europe are broadly similar to the NNR and FAO recommendations. These were reviewed recently by the EFSA [7]; see also [6]. From a European-wide perspective, recommendations were also published by the WHO in their European Action Plan for Food and Nutrition Policy 2007-2012 [10]. In addition to dietary targets, the WHO identified a need to promote the reformulation of mainstream food products in order to reduce the amount of salt, added sugar, SFAs and TFAs in order to improve the availability of healthier products, by establishing a dialogue with food manufacturers.

The FAO review also evaluated the association between fat intake and health [3]. Evidence was classified as convincing, probable, possible and insufficient. The main health associations in adults that were supported by convincing or probable evidence are detailed in Table 3. From this table it can be seen that the convincing evidence largely relates to changing the fatty acid profile, by reducing the intake of SFA specifically the SFA rich in C12-C16 SFA and replacing it with unsaturated fat either MUFA or PUFA, in order to reduce total and LDL cholesterol or to improve the total to HDL cholesterol ratio and also reduce the risk of CHD or CHD events. A meta-analysis of randomized controlled trials (RCT) quantified this benefit concluding that cis-MUFAs or PUFAs were the most effective replacements of dietary SFAs to reduce CHD risk [11]. It was calculated that the replacement of $1 \%$ carbohydrate energy with cis-MUFA or PUFA improved Total-C: HDL-C ratio by circa 0.03 $(P \leq 0.001)$, whereas LDL-C was reduced by circa 0.1 $\mathrm{mmol} / \mathrm{L}(P \leq 0.01)$ when replaced by MUFA and circa $0.2 \mathrm{mmol} / \mathrm{L}(P \leq 0.001)$ when replaced by PUFA. The same replacement with SFA increased LDL-C by circa $0.03 \mathrm{mmol} / \mathrm{L}(P \leq 0.001)$.

The FAO review also identified that there was evidence, at the possible level, between SFA intake and increased diabetes risk and possible associations between MUFA or n-6 PUFA and the reduced risk of symptoms of the metabolic syndrome [3]. However, higher intakes of n-6 PUFA (>11\%) were possibly associated with lipid peroxidation especially when tocopherol intake is low. Leading to the maximum intake range of $6 \%-11 \% \mathrm{E}$. A reduced risk of total CHD events and stroke were possibly associated with n-3 PUFA intake.

There was insufficient evidence to link total fat or any fat component consumption to cancer.

\subsection{Fat Intakes}

Fat intakes in a number of EU States was reviewed by EFSA [7]; typically adults (19 - 64 years old) in Western Europe consume 33\% - 38\% E total fat, notable exceptions are Greece where fat intake is on average $45 \%$ $47 \%$ and Norway and Finland where intakes were $31 \%$ $33 \%$ E. In Eastern Europe, total fat intakes tend to be higher at circa $40 \%$ E. Less data was reported for SFA, but in all countries except for Portugal average population intakes exceed $10 \% \mathrm{E}$, populations that consume a

Table 3. Health associations with fatty acids for which there is convincing or probable evidence.

\begin{tabular}{|c|c|c|c|}
\hline Type of fat & Fat intake \% E & Convincing evidence & Probable evidence \\
\hline Total fat & $20-35$ & None & $\begin{array}{l}\text { No relation with CHD events, fatal CHD, } \\
\text { total cancer, or cancer subtypes }\end{array}$ \\
\hline SFA & 10 & $\begin{array}{l}\text { C12:0-16:0 increase LDL and total/ HDL ratio in } \\
\text { comparison to cis MUFA or PUFA; increase LDL but } \\
\text { no effect on total/HDL in comparison to carbohydrate }\end{array}$ & None \\
\hline MUFA & $\begin{array}{c}\text { By } \\
\text { difference }\end{array}$ & $\begin{array}{l}\text { Reduce LDL and total/HDL ratio when substituting } \\
\qquad \text { SFA (C12:0-16:0) }\end{array}$ & None \\
\hline $\begin{array}{l}\text { Total PUFA }(\mathrm{LA}+\mathrm{ALA}+ \\
\qquad \mathrm{EPA}+\mathrm{DHA})\end{array}$ & $6-11$ & $\begin{array}{l}\text { Reduce LDL and total/HDL ratio when } \\
\text { substituting SFA (C12:0-16:0) }\end{array}$ & $\begin{array}{l}\text { Reduce risk of metabolic syndrome } \\
\text { components, diabetes }\end{array}$ \\
\hline Of which: n-6 PUFA & $2.5-9$ & Reduce risk of CHD events when PUFA replace SFA & \\
\hline (LA) & $0.5-2$ & Essential & None \\
\hline (ALA) & $>0.5$ & Essential & \\
\hline TFA & $<1$ & $\begin{array}{c}\text { Reduce HDL and increase total/HDL ratio in } \\
\text { comparison to SFA (C12:0-C16:0), cis MUFA or } \\
\text { PUFA increase risk of CHD events }\end{array}$ & $\begin{array}{l}\text { Increase risk of fatal CHD and sudden } \\
\text { cardiac death, increase risk of metabolic } \\
\text { syndrome components, diabetes }\end{array}$ \\
\hline
\end{tabular}

E: Energy; SFA: saturated fatty acids; MUFA: monounsaturated fatty acids: PUFA: polyunsaturated fatty acids; LA: linoleic acid, ALA: alpha linolenic acid, EPA: eicosapentaenoic acid; DHA: docosahexaenoic acid; TFA: trans fatty acids (Source FAO 2010). 
higher proportion of dairy products (Netherland, Denmark and Norway?) were typically $>14 \%$ E SFA, despite lower total fat intakes. TFA intakes, where recorded, were in the range $0.4 \%-1.2 \% \mathrm{E}$.

Intake of MUFA were $11 \%$ - $22 \% \mathrm{E}$ with Greece consuming at the highest level; typically around $11 \%-12 \%$ of dietary energy intake is derived from MUFA in most Northern and Western European States compared to $18 \%$ - 22\% in Spain and Greece where the effects of the Mediterranean diet prevail.

PUFA intake were $4.5 \%-9.2 \% \mathrm{E}$ and thus tend to be on the low end of the target range for PUFA; intake was highest in Austria, Lithuania and Hungary. Limited data was presented in respect the proportion of the PUFA, which was n-3 fatty acids and n-6 fatty acids. Overall the intake of PUFA was close to the target range proposed, but there may be a need to increase the amount of n-3 fatty acids.

Looking at the data as a whole, in Western Europe, the main dietary challenge is to reduce SFA as it is typically the main FA that exceeds target range recommended. To improve the fat quality of the diet, it is necessary to reduce SFA intake and replace it with sources of MUFA and PUFA, while in Eastern Europe the challenge is two-fold to reduce both total and SFA intake.

National Diet and Nutrition Survey (NDNS) provides information related to the population's food intake for young people aged 1.5 - 18 years and adults. Data were collected on an approximate 10-year cycle until 2001 [12], when the format of data collection changed to a rolling survey, each year data is added, currently there are three years of rolling data available commencing in 2008 and representing approximately 1491 adults and 1582 young people.

Figure 3 includes data from the last decade relating to the adult profile of fat intake from 2001 to 2011. However due to a number of developments in the approach and different sampling technique between the 10-year data and the rolling programme the findings are only indicative of changes in dietary habits. Nevertheless the changes in fat profile are modest, with Figure 3. a small reduction in SFA \% of $\sim 0.5 \% \mathrm{E}$ and small increase in MUFA of $\sim 0.8 \%$ E. Intake of PUFA has been effected to an even smaller degree $(\sim 0.2 \% \mathrm{E})$ over the decade. Consequently there has been an improvement in the fat profile, but to a very modest degree and over this period both total fat and SFA intake have reduced, in the case of SFA from an average of $32 \mathrm{~g}$ in 2001 to $25 \mathrm{~g}$ in 2011 (28.8 $\mathrm{g}$ in men and $22 \mathrm{~g}$ in women) compared to a reference intake of $20 \mathrm{~g}$.

\subsection{Sources of Fat in the UK Diet}

The major food groups supplying SFA in the diet in the NDNS surveys of 1981, 1991 and 2001 have been previously been compared [9]; this data is now compared to the most recent SFA intake data from year 3 (2010/11) of the NDNS Rolling Programme [13] in Figure 4.

From this figure it can be seen that over the 40-year period there has been a considerable alternation in the key sources of SFA in the diet. During the Eighties and Nineties considerable progress was made as people switched to lower fat dairy products, for example, from whole milk to semi-skimmed milk and to leaner cuts of meat; while the move from butter to margarines and low fat spreads has also had a marked effect on SFA intake from this source. However over this period the role of manufactured foods as a source of SFA has become more important with a greater intake of SFA from cereal and cereal-products and fried vegetables including potatoes. It can be seen that in the meat and meat products category the SFA has not reduced further during the last decade. Within this category the SFA derived from meat products has increased. This category will include pies, pastries, sausages and burgers but also the prepared and

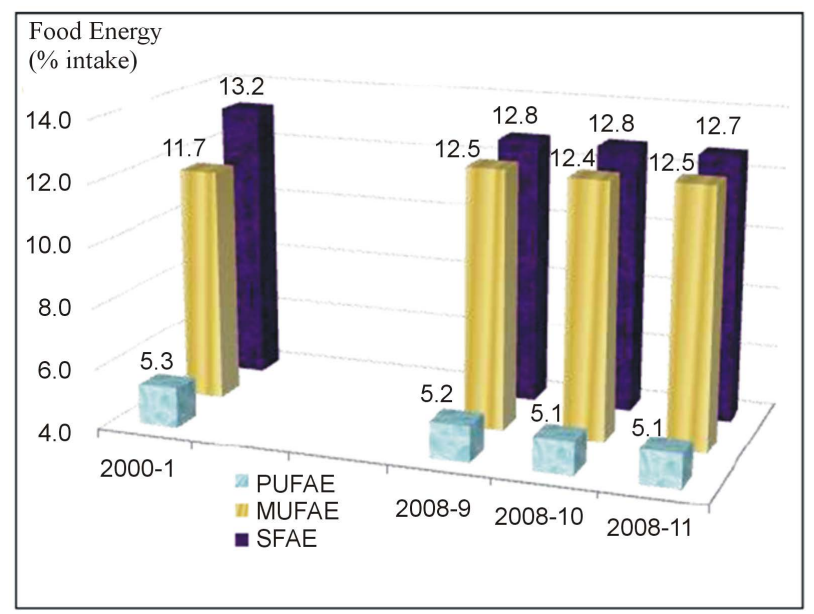

Figure 3. Proportion of food energy consumed as SFA, MUFA and PUFA in adult from NDNS surveys (Source: NDNS).

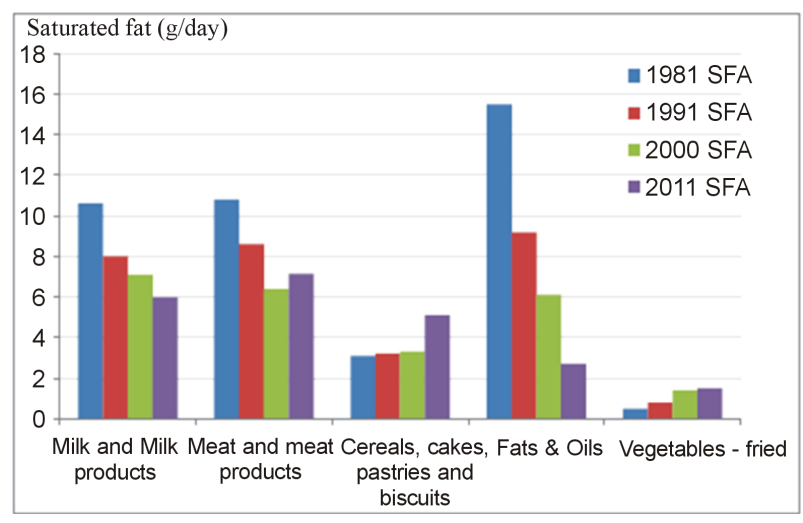

Figure 4. Main food source of SFA in the diet of adults from 1981-2010/11 (Source NDNS surveys and analysis from Minihane and Harland 2007, Palmer 2013). 
par-cooked meat dishes, breaded and coated meat products, many of which may be consumed outside of the home.

An analysis of first two years of the NDNS Rolling programme identified that those adults that met dietary guidelines for fat and SFA consumed more skimmed milks, chicken and turkey dishes, white fish (not fried) and shellfish and wholemeal breads, while non-achievers consumed more coated chicken, meat pies and pastries, cheese, whole milks and white bread. It appears that the achievers have reduced the fat content of their diet by focussing on lower fat/higher fibre alternatives within the same category of foods rather than introducing different foods such as oils, legumes, nuts and seeds [14]. Those achieving the fat and SFA targets consumed a greater proportion of their $\mathrm{E}$ intake as protein and hence may not have improved the fat profile of the diet.

The situation in young people (4 - 18 years old) is comparable to some degree, but in this group fried vegetables including potatoes and savoury snacks supply a greater proportion of SFA intake (8\%) and sugar, preserves and confectionary products a further (7\% E) [13]. This trend was previously reported after analysis of 1998 NDNS data in young people, at this time fried vegetables and snacks accounted for $14 \%$ of SFA intake and sugar, preserves and confectionary products provided $9 \%$ of SFA [15]. While there may have been a marginal reduction in the grams consumed of these categories of foods, much more important, are technological improvements that have reduced the fat content of the foods, for example, the move from deep fried to oven chips and also the reduction in the proportion of SFA in the frying oils. For example, typically a potato contains $\sim 0.1 \%$ fat, while chips contain $\sim 10 \%$ fat and savoury snack may be $\sim 35 \%$ fat; consequently the oil profile of the finished food is derived from the oil the potato is fried in. A $100 \mathrm{~g}$ serving of potatoes chips contains $10 \mathrm{~g}$ fat, which will comprise $0.7 \mathrm{~g}$ SFA if fried in hi-oleic rapeseed oil and $5 \mathrm{~g}$ is fried in palm oil. The reduction in SFA intake in the category, fried vegetables including potatoes and savoury snacks, may well result from the change in profile of the vegetable oils used in food manufacture, particularly frying oils where there has been increased use of rapeseed and sunflower either alone or as blends, largely these have replaced palm oils with a SFA content of 50\% compared to rapeseed $6.6 \%$ SFA) and sunflower (12\% SFA) or high oleic sunflower (10\% SFA).

It has previously been identified that people find it difficult to adopt multiple changes to their diet [16,17], and as can be seen from Figure 4, are more likely to change to a healthier option within the same category rather than add new foods to the diet. How to encourage dietary choices that result in a healthier fat profile, while at the core at much dietary advice, appears difficult to achieve in practice. WHO in their 2008 recommendations recognised this quandary and, in addition to dietary targets identified a need to enhancing the availability of healthier products by establishing a dialogue with food manufacturers [10]; thus promoting the reformulation of mainstream food products in order to reduce the amount of SFA, TFA salt and added sugar.

\section{MEETING FAT RECOMMENDATIONS BY STEALTH}

The growing importance of prepared and ready meals in our daily diet and the consumption of food outside the home emphasises the importance of the role that industry can play in improving the diet. In addition the proportion of the SFA that is contributed by manufactured foods, for example meat based ready meals and convenience meat products increased by $9.9 \%$ between 2007 and 2010 and food consumed outside the home, which increased in monetary value by $7.2 \%$ for the same period [18]. Quantifying the impact that industry has already made to nutrient supply is not easy. However in the oilseeds market place it is clear that quite major changes have taken place, some of which were not prompted by the demand for healthier oils while others changes will have been prompted by short-term supply difficulties and price, for example, the effect of rapeseed oil supply difficulties can be seen in 2010 in Figure 2.

In order to understand how changes in the oil supply market may have had an impact on FA intake and how the fatty acid profile of the market place has changed over recent years, the oil tonnages used for edible purposes data from Figure 2 has been converted into a fatty acid profile for the market place. Book values for the fatty acid analysis were used to convert tonnages of the various oils into tonnages of SFA, MUFA and PUFA; see Figure 5. However a further key change in the market place is the introduction of hi-oleic sunflower, which over the last 3 - 4 years has grown from a low base and now accounts for approaching one third of the sunflower grown in the EU. The dotted lines in Figure 5 indicate the impact of the different fat profile of the hi-oleic sunflower at current levels of use, compared to the market profile if conventional sunflower had continued to be grown (solid line); from this figure it can be seen that hioleic sunflower has had a marked effect on fatty acid availability in the market place, while SFA remains unchanged the proportion of MUFA has increased. Data for the n-3 PUFA are not shown due to variations within the relatively small quantities found in all but rapeseed oil.

The popularity of hi-oleic sunflower and increasingly hi-oleic rapeseed is due to the fact that hi-oleic oilseed oils deliver technological properties that conventionally have not been associated with these oils, such as being particularly suited as a replacement of conventional fry- 
ing oils. Frying oils use has evolved over the years, initially the undesirability of hydrogenated oils because of their high content of TFA, led to them being replaced by palm olein, which is high in SFA. More recently the challenge has been to replace the oxidatively stable palm olein with suitable alternatives. The hi-oleic oils have the benefit of being oxidatively stable and low in SFA and are suitable for use in both home and commercial frying. The low LA of hi-oleic rapeseed makes it of particular interest to commercial fryer as it results in a lower polymerisation of oil. Polymerization, causes discolouring of the oil and can clog frying and manufacturing equipment, which is important when oils are used for several batches, or continuously as they commercially. This polymerization can also form a film on kitchen and frontof-the-house counters in restaurants that fry foods. Oils dismissed because of their discolouration or oxidations are now being replaced by hi-oleic oils. Clearly replacing palm olein (50\% SFA content) with hi-oleic oilseed oils with a much lower SFA content has not only had a major impact on the FA profile of the market place but also a significant effect on the FA profile of finished foods, as many fried and manufactured foods can have a fat profile that represents the oil that they were cooked in. Thus changing the oil used by the food manufacturer allows a beneficial change in nutrition profile of products with no intervention by the consumer themselves. Provided the product with a healthier fat profile has similar eating qualities the consumer will be largely unaware of the healthy changes they are making to their diet.

Figure 6 is a graphical representation of the changes in the proportion of food energy that have been recorded by adults participating in the NDNS and also the Family Food Survey [18-20]. The FFS provides detailed information on purchases, expenditure and derived nutrient content of food purchases from a large household survey covering the UK. Foods are reported at a detailed level and patterns are related to demographic characteristics. The FFS data collection differs from NDNS in a number of ways, as all foods brought into the home are taken into account and intake proportioned throughout the household, in addition food wasted may not be fully adjusted for, with the result that intake data from the FFS are generally higher than NDNS. The FFS data are available on an annual basis and therefore values are available for the entire period from 2001-2011.

It is interesting to compare the profiles of Figures 5 and 6 . It can be seen there are some similarities. The FFS data represent all food brought into the home and thus not surprising the FA profile of this data is more comparable to the adjusted FA profile of the market place in Figure 5. The similarity in profile highlights the relationship between the availability of oils in the market place and the profile of consumption and serves to emphasize the opportunity for manipulating the dietary FA

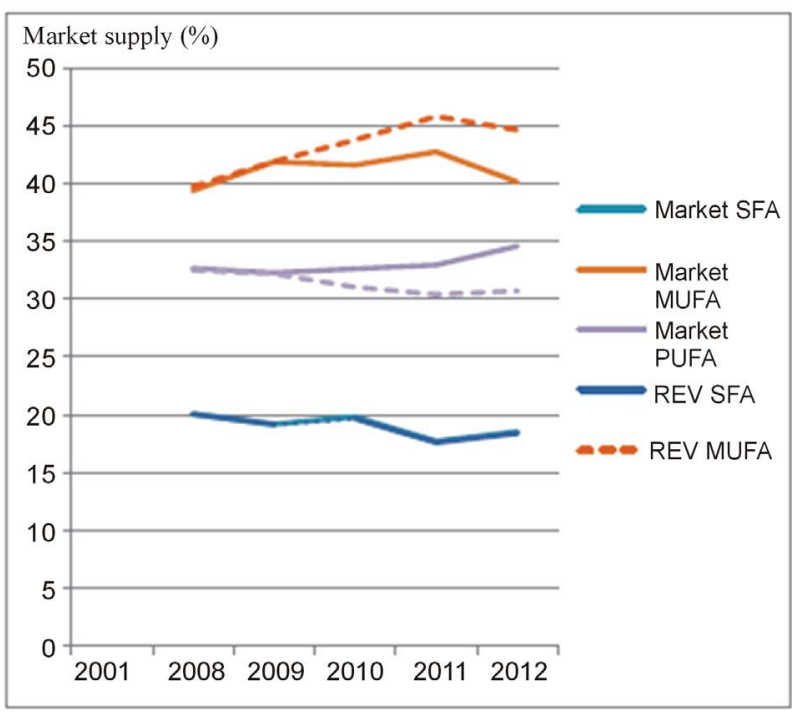

Figure 5. UK market edible vegetable oils: the proportion of SFA, MUFA and PUFA including impact of hi-oleic sunflower oil. * Rev data refers to data where adjustment has been made to fat composition to take account for introduction of hi-oleic sunflower into the market.

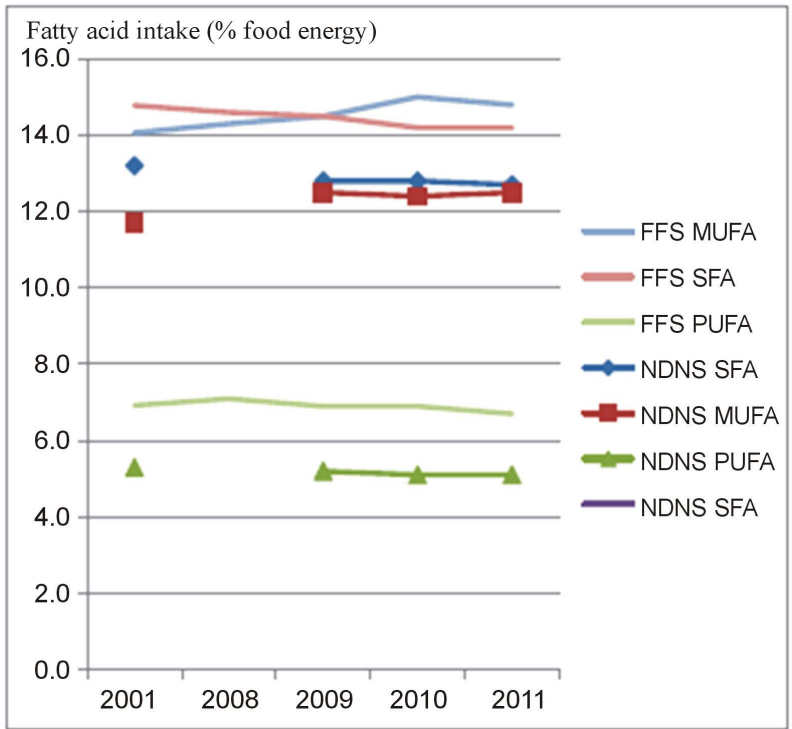

Figure 6. The intake of SFA, MUFA and PUFA as \% food E from the FFS and NDNS.

composition through market supply. This could be by adjustment to both the nature and amount of oils used in manufactured foods consumed both within and outside the home or by changes to the composition of the oil to a healthier profile through plant breeding. In this respect the hi-oleic oils can be considered some of the first generation nutritionally improved oilseed crops, but further developments particularly in respect of their ALA content could be worthwhile, as it is the generally the n-3 FA that are in short supply in the diet. It is likely that foods produced with a healthier fat profile, will largely have a 
taste profile and be similar to regular products, thus the consumer will need to make minimal changes to the foods that they select and can continue to consume their preferred foods, hence dietary changes can be made in such a way that requires minimal consumer intervention and allows changes to fat profile to be achieved by stealth.

By using the market supply to drive dietary change those sectors of the population most resistant to healthy eating messages and dietary change, and least likely to make dietary interventions, move to a healthier FA profile of intake. From an industry perspective the use of such oils can support WHO and National initiatives that are looking for industry pledges that offer sustained longterm reductions in SFA supply.

\section{ACKNOWLEDGEMENTS}

The NDNS analysis was conducted, in part, by Paige Palmer graduate of Bath Spa University as part of her BSc Food and Nutrition in Practice module. .

\section{REFERENCES}

[1] Department of Health (1991) Dietary reference values of food energy and nutrients for the United Kingdom. Report of the Panel on Dietary Reference Values of the Committee on Medical Aspects of Food Policy, London.

[2] Henderson, L., Gregory, J., Irving, K. and Swan, G. (2003) The national diet \& nutrition survey: Adults aged 19 to 64 years. Volume 2 Energy, Protein, Carbohydrate, Fat and Alcohol Intake. HMSO, London.

[3] FAO (2010) Fats and fatty acids in human nutrition. Report of an Expert Consultation in Food and Nutrition Paper 91. FAO, Rome.

[4] EFSA Panel on Dietetic Products Nutrition and Allergies (NDA) (2011) Scientific opinion on the substantiation of health claims related to polyphenols in olive and protection of LDL particles from oxidative damage (ID 1333, 1638, 1639, 1696, 2865), maintenance of normal blood HDL-cholesterol concentrations (ID 1639), maintenance of normal blood pressure (ID 3781), "anti-inflammatory properties" (ID 1882), “contributes to the upper respiratory tract health” (ID 3468), “can help to maintain a normal function of gastrointestinal tract” (3779), and "contributes to body defences against external agents” (ID 3467) pursuant to Article 13(1) of Regulation (EC) No 1924/20061. EFSA Journal, 9, 2333.

[5] Simopoulos, A.P. (2001) n-3 fatty acids and human health: Defining strategies for public policy. Lipids, 36, S83-S89. http://dx.doi.org/10.1007/s11745-001-0687-7

[6] Aranceta, J. and Perez-Rodrigo, C. (2012) Recommended dietary reference intakes, nutritional goals and dietary guidelines for fat and fatty acids: A systematic review. British Journal of Nutrition, 107, S8-S22. http://dx.doi.org/10.1017/S0007114512001444
[7] EFSA Panel on Dietetic Products Nutrition and Allergies (NDA) (2010) Scientific opinion on dietary reference values for fats, including saturated fatty acids, polyunsaturated fatty acids, monounsaturated fatty acids, trans fatty acids, and cholesterol. EFSA Journal, 8, 1461.

[8] Nordic Council of Ministers (2013) Nordic nutrition recommendations. Part 1, summary, principles and use. Nord, Copenhagen. http://dx.doi.org/10.6027/Nord2013-009

[9] British Nutrition Foundation (2005) Cardiovascular disease: Diet, nutrition and emerging risk factors. The Report of the British Nutrition Foundation Task Force, Blackwell Publishing, Oxford.

[10] WHO (2008) WHO European action plan for food and nutrition policy 2007-2012.

http://www.euro.who.int/_data/assets/pdf_file/0017/744 02/E91153.pdf

[11] Mensink, R.P., Zock, P.L., Kester, A.D. and Katan, M.B. (2003) Effects of dietary fatty acids and carbohydrates on the ratio of serum total to HDL cholesterol and on serum lipids and apolipoproteins: A meta-analysis of 60 controlled trials. American Journal of Clinical Nutrition, 77, 1146-1155.

[12] Henderson, L., Gregory, J., Irving, K. and Swan, G. (2003) The national diet and nutrition survey: Adults aged 16-64 Years. Vol. 1. The Stationery Office, London.

[13] Palmer, P. (2013) Identify the key foods that provide saturated fatty acids to the adult diet and identify those where the composition could be enhanced in order to improve the fat quality of the diet by the use of omega-9 rich rapeseed oil. Final Year Project for School of Enterprise, Society and Environment, University of Bath Spa, Bath.

[14] Harland, J.I., Buttriss, J. and Gibson, S. (2012) Achieving eatwell plate recommendations: Is this a route to improving both sustainability and healthy eating? Nutrition Bulletin, 37, 324-343. http://dx.doi.org/10.1111/j.1467-3010.2012.01988.x

[15] Minihane, A.M. and Harland, J.I. (2007) Impact of oil used by the frying industry on population fat intake. Critical Reviews in Food Science and Nutrition, 47, 287-297. http://dx.doi.org/10.1080/10408390600737821

[16] De Looy, A., Auty, P.L. and Coates, C. (1991) Is our dietary advice effective? Proceedings of the Nutrition Society, 51, 63-69. http://dx.doi.org/10.1079/PNS19920011

[17] Fehily, A.M., Vaughan-Williams, E., Shiels, K., Williams, A.H., Homer, M., Bingham, G., et al. (1991) Factors influencing compliance with dietary advice: The diet and reinfarction trial (DART). Journal of Human Nutrition and Dietetics, 4, 33-42. http://dx.doi.org/10.1111/j.1365-277X.1991.tb00074.x

[18] Defra (2011) Family Food 2010. A National Statistics Publication. www.defra.gov.uk/statistics/foodfarm/food/familyfood/

[19] Bates, B., Lennox, A., Bates, C. and Swan, G. (2011) National diet and nutrition survey, rolling tables from years 1 and 2 (combined) of the rolling programme (2008/2009-2009/10). 
http://www.dh.gov.uk/prod_consum_dh/groups/dh_digital assets/documents/digitalasset/dh_128550.pdf

[20] (2012) NDNS_Yr3_Chapter5_TABLES_FINAL_01082012.
Xls.

http://transparency.dh.gov.uk/2012/07/25/ndns-3-years-re port/

\section{ABBREVIATIONS}

ALA: Alpha Linolenic Acid

C: Cholesterol

COMA: Committee on Medical Aspects of Food Policy

DHA: Docosahexaenoic Acid

DRV: Dietary Reference Value

E: Energy

EPA: Eicosapentaenoic Acid

FA: Fatty Acid

FAO: Food and Agriculture Organization

FFS: Family Food Survey

HDL: High Density Lipoprotein
LA: Linoleic Acid

LDL: Low Density Lipoprotein

MUFA: Monounsaturated Fatty Acids

NDNS: National Diet and Nutrition Survey

NNR: Nordic Nutrient Recommendations

PHVO: Partially Hydrogenated Vegetable Oils

PUFA: Polyunsaturated Fatty Acids

RCT: Randomized Controlled Trial

SFA: Saturated Fatty Acids

TFA: Trans Fatty Acids

WHO: World Health Organization 